\title{
AN EARTHQUAKE CATASTROPHE DAMAGE ASSESSMENT MODEL WITH PARTICULAR REFERENCE TO CENTRAL NEW ZEALAND \\ David J. Dowrick*
}

\begin{abstract}
SYNOPSIS:
This paper discusses an assessment of the total earthquake damage that could be expected to occur in central New Zealand in two large specific events. Damage was defined as a percentage of replacement value of any property in the affected area, being in fact the properties insured by the New Zealand South British Insurance Group. A definition of an insurance catastrophe event was proposed, and two levels of risk were examined, namely annual risks of 1 in 1000 and 1 in 9000. Sig-. nificant total damage levels were formed and major uncertainties in all factors in the risk analysis are discussed.
\end{abstract}

\subsection{INTRODUCTION}

In the study on which this paper is based, it was required to firstly postulate the levels of risk to be used and corresponding specific earthquake events, and then to estimate the total insurance liability via the total material damage cost for all of the properties insured in the highest cumulative seismic risk exposure zone for the insurance company concerned. This estimate was required for reinsurance purposes. Damage to the buildings, their services and their plant were individually considered.

For the specific events, each individual property had to be classified for damage vulnerability and the level of shaking to which it would be subjected had to be determined. The effects of possible earthquake induced geological hazards, such as landslides, liquefaction faulting and dam failure, and earthquake induced fires were also taken into account.

In order to handle the large number of properties involved a computerized data handling system was developed, and for properties of smaller value (e.g. houses) and those subjected to lower levels of shaking average data rather than specific were used.

The computerisation facilitated some parametric calculations which helped to demonstrate the sensitivity of the results to various uncertainties.

\subsection{TECTONICS, GEOLOGY AND SEISMICITY}

Às discussed in detail by stevens (1980), New Zealand is situated on the junction between two distinct structural components of the earth's crust, namely the Pacific and the Australian-Indian tectonic plates. The Pacific plate is thrusting under the Australian-Indian plate, and there is also a differential horizontal movement between the two plates.

This crustal activity induces strong earthquakes to occur at a rate which is moderately high on a world scale. The central part of New Zealand including the

*Structural engineer and partner, Brickell,

Moss and Partners, Consulting Engineers,

Surveyors and Planners, wellington.

BULLETIN OF THE NEW ZEALAND NATIONAL SOCIETY FOR EARTHQUAKE ENGINEERING, VOL. 16, NO. 3, SEPTEMBER 1983
Wellington area lies squarely on the axis of greatest seismicity which runs approximately SW-NE through the country, as indicated by the epicentres of New Zealand's larger historical earthquakes which are plotted on Fig. 1. The largest shallow earthquakes are generally associated with displacements of major surface faults which are also aligned in the above direction, as also

Future major earthquakes in the Wellington area are most likely to have their origins on one or other of the longer local faults which have moved in recent times, i.e. within the last 10-20,000 years. These faults are capable of generating earthquakes of magnitude 8 or so on the Richter scale, as indicated by the maximum magnitudes estimated by Lensen (1981) given below:

\begin{tabular}{ll} 
Fault & \multicolumn{1}{c}{$\max$} \\
Kapiti & $8.3-8.4$ \\
Owhariu & 8.0 \\
Wellington & 8.2 \\
West Wairarapa & 8.2
\end{tabular}

The above values should be compared with the largest known magnitude for New Zealand, which was of the 1855 earthquake of approximately $\mathrm{M}=8.0$ and which was centred on the West Wairarapa fault.

The strong seismic activity in the centre of New Zealand since 1840 shown on Fig. 1, has been given numerical expression in the seismicity study conducted by Smith $(1978 \mathrm{a}, \mathrm{b})$ and shows clearly that the centre of New Zealand has recently had the highest seismic risk level for the whole country. At any site within the central risk area, having average ground conditions, intensity MMIO is likely to occur with an average return period about 1000 years. At sites where the soil is poor the intensity will be higher for the same return period.

Smith has recently been re-evaluating the seismic risk in New Zealand, and his revised figures indicate a slightly lower risk in the Wellington region. For example the return period for MMl0, at sites with average ground conditions in Wellington, has been provisionally given as 1180 years (Smith, 1981a). shown on Fig. 1. 


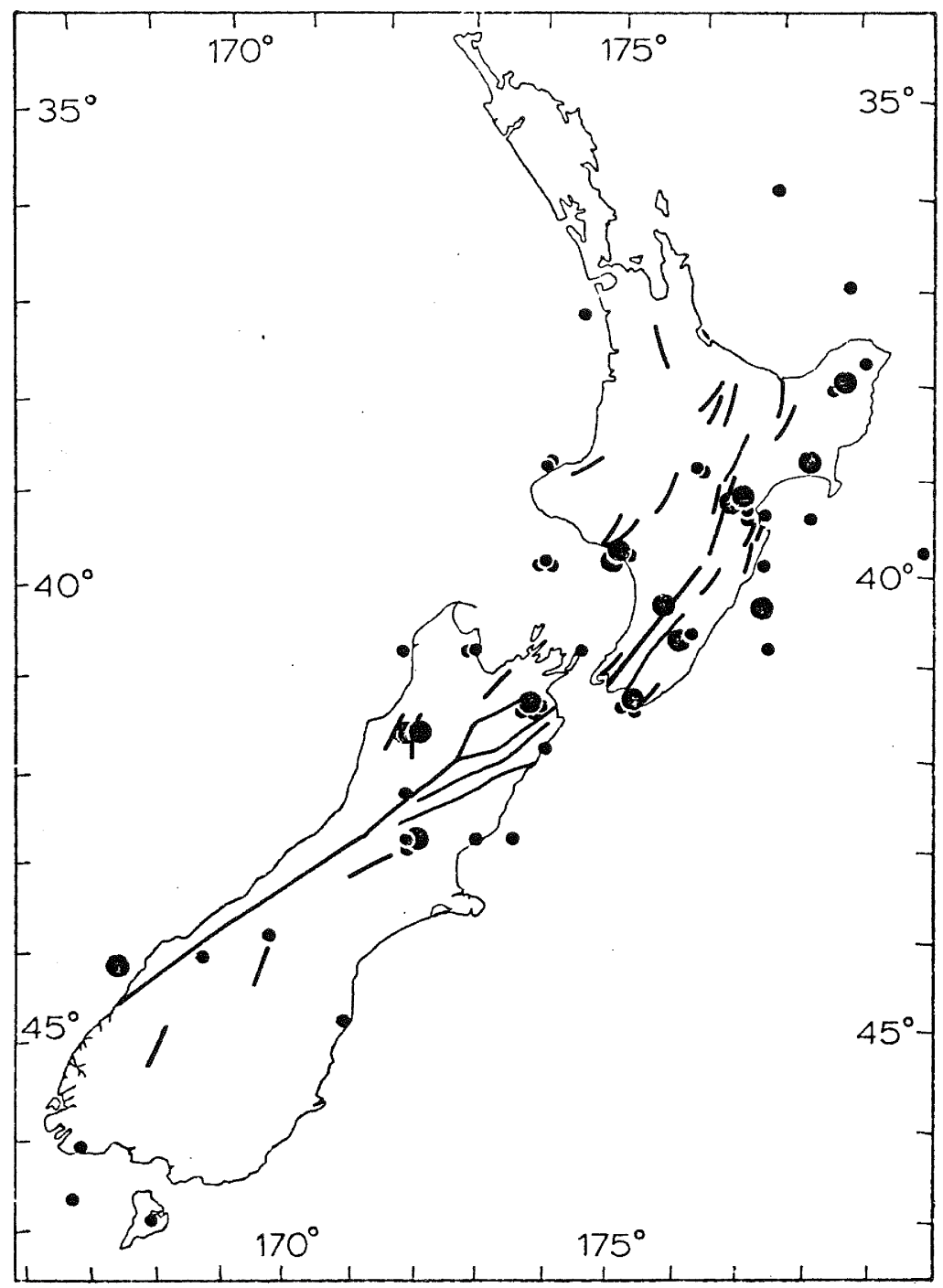

- PRINCIPAl active faults (After Stevens, 1980)

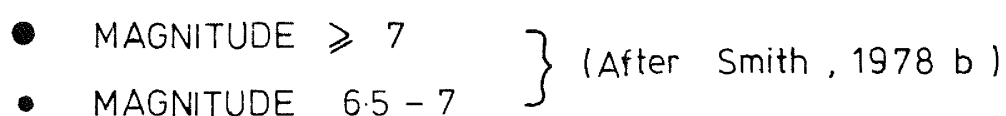




\subsection{DEFINING THE CATASTROPHE EVENTS}

\subsection{Insurance Aspects}

In general terms the catastrophe earthquake is a very large and, correspondingly, rare event. For the purposes of reinsurance, the catastrophe earthquake is defined essentially by two related factors -

(i) The magnitude of the event, and

(ii) its annual probability of occurrence, or average return period.

The expected loss and hence insurance liability is proportional to (some power $b$ of) the earthquake magnitude, $M$, and the rate of occurrence of the loss is inversely proportional to the return period. T. Hence the average annual loss may be expressed as -

$$
L / y r \propto \frac{M^{b}}{T_{r}}
$$

In very approximate terms, as we increase the rarity of the event being considered both the magnitude and return period increase and from equation (1) it is obvious that the average annual loss may be fairly constant, at least over a moderate range of return periods. If this were proven to be the case, the actual $\mathrm{M}, \mathrm{T}$ pair could be chosen arbitrarily and with impunity as far as the average annual loss is concerned.

However, the actual amount of the catastrophe liability may be crucial if it is large in relation to the geographical spread of risks and to the capacity of the Insurers to meet valid claims. In this case it is clearly important to ascertain the extent of the liability due to a very large and hence very rare event. It may be that the top of the range of magnitudes of possible earthquakes cannot be fully covered. Bearing in mind that such events will in general be very rare, and at some level cannot be provided for, it would be a matter of company policy to decide what upper limit of rarity to fully cover. This would clearly be a somewhat arbitrary decision.

The arbitrariness of this decision will be compounded by the inherent uncertainty in the estimates of the expected liabilities and return periods of rare events as described below.

\subsection{Seismicity Aspects}

In order to evaluate the insurance implications of catastrophic earthquakes it is necessary to examine the effects of an event of suitable size and rarity. We must choose an event which is large enough but not so rare as to be unrealistically pessimistic. The background to the choice is described below.

Bearing in mind the population distribution and the high focus of seismic risk in the centre of New Zealand, it is apparent that the most likely, worst loss due to a single earthquake in New Zealand would be caused by a large earthquake encompassing Wellington City. Therefore the initial premise was that in the catastrophic event Wellington City would be in or near the epicentral area, the latter being defined as the zone experiencing an intensity of IX or more on the Modified Mercalli scale, which implies strong ground shaking and severe damage to many buildings. This intensity of shaking could be caused by. Richter magnitudes of about $M=6.7$ and greater (Smith, 1978 a).

At present there is a consensus of seismological opinion in New Zealand that the maximum size of earthquake that could occur in New Zealand generally is $M=8.5$, and the largest likely to occur in the Wellington region is magnitude $M=8.2$, or possible slightly greater on the Kapiti fault (Section 2.0). Thus it may be assumed that the catastrophe magnitude lies in the range 6.7 to 8.2 .

In the present absence of means of predicting the size, location or timing of the next (large) earthquake in New Zealand (Evison, 1981), the best method of assessing the risk of future earthquake events is to make probabilistic estimates based on the history of past earthquakes, interpreted in the light of the geological framework, as discussed below.

\subsection{Defining the Catastrope Events}

The first step is to determine the magnitude and general location of the earthquake which has the maximum likelihood of causing a given intensity of shaking in Wellington and Lower Hutt. This step was based on the latest seismicity model of New Zealand, as currently being developed by a seismic risk study group for devising the New Zealand earthquake code. This step had reached a sufficiently definitive stage for its use in this study, thanks to the courtesy of the risk study chairman (Smith, 1981a).

In the above group's seismicity model (Smith, 1981 b) various sectors of New Zealand had different seismicity levels assigned to them according to both the seismic history and to geological factors. The zone embracing Wellington was assigned a magnitude-frequency relationship of

$\log \mathrm{N}=4.474-1.13 \mathrm{M}\left(\mathrm{M}_{\max }=8.2\right)$

where $\mathrm{N}$ is the number of events of magnitude $M$ or greater, occurring in an area of $1000 \mathrm{~km}^{2}$ per year. The smoothed form of the above equation adopted for this study is shown on Fig. 2 .

As well as using the above data, it was necessary to allow for the distribution of two different types of earthquakes ( $A$ and $B$ ) affecting the centre of New - Zealand. Smith (1978 a) showed that a given magnitude of Type $B$ earthquake affects a much larger area than the same magnitude Type A earthquake, and that these earthquakes tend to occur in fairly distinct geographical regions.

In order to find the most likely size of event causing a given intensity in a specified area, it was necessary to divide the magnitude-frequency distribution 

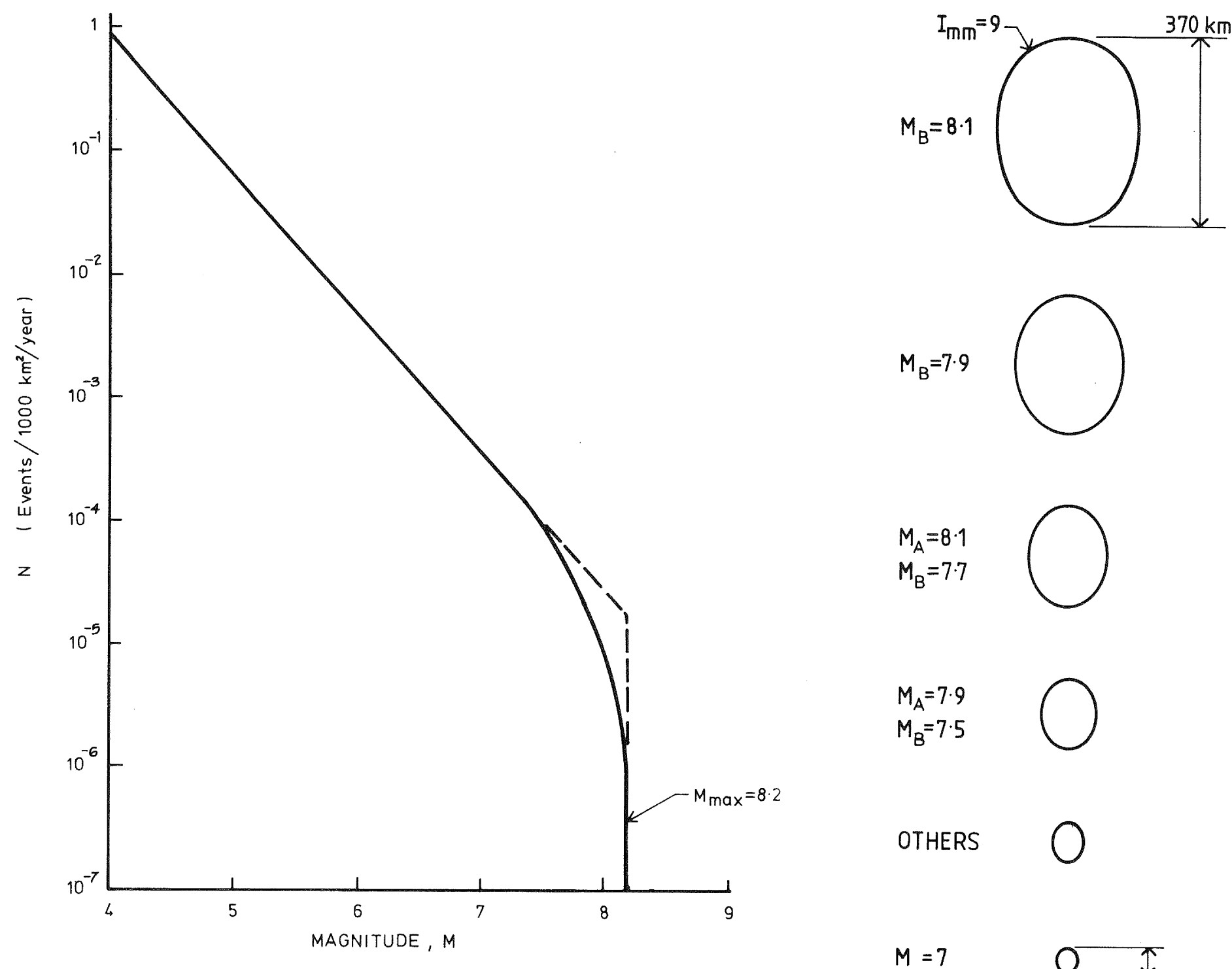

Approximate Annual Risk of causing $I_{\mathrm{mm}}=9$

in Wellington and Lower Hutt
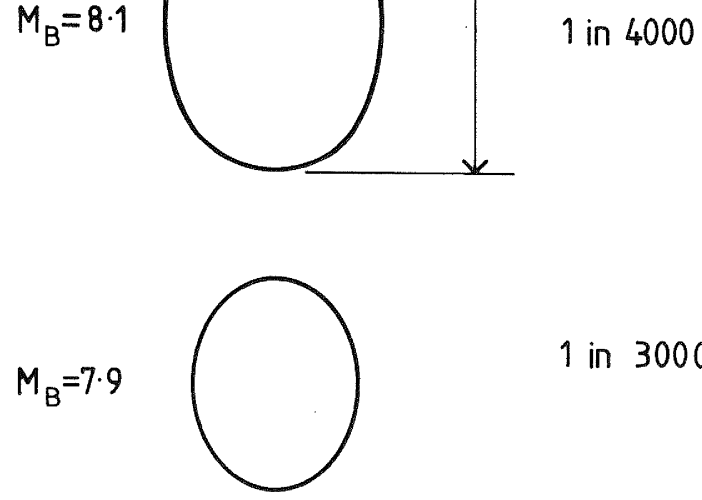

1 in 3000

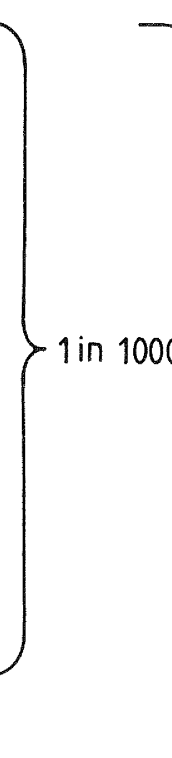

$M_{A}=8 \cdot 1$

$M_{B}=7 \cdot 7$

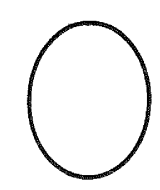

1 in 3000

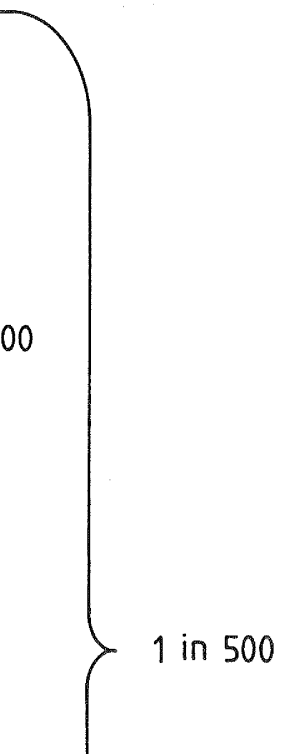

$M_{A}=7 \cdot 9$

$M_{B}=7 \cdot 5$

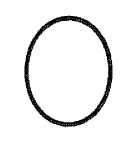

1 in 3000

$\begin{array}{lll}\text { OTHERS } & 1 \text { in } 2500 \\ M=7 & \frac{\sqrt{45 \mathrm{~km}}}{2 \text { in } 5000}\end{array}$


(Fig. 2) into a series of magnitude increments each having a given probability of occurrence. For this purpose the magnitude increment adopted was $\Delta M=0.2$, and for convenience each increment was labelled by the mid-point of the range, e.g. the increment at the largest end of the scale (i.e. 8.0 to 8.2), was called a magnitude 8.1 earthquake. The comparative sizes in this resulting range of earthquakes is shown on Fig. 3., the size being illustrated by the area in which the intensity is MM9 or greater. This area is an idealized, elliptical shape, using the model proposed by Smith (1978 a), with the minor axis 0.8 times the major axis as is appropriate for the Wellington area.

The final step was to calculate the risk of each of the above earthquake sizes giving rise to given intensities in Wellington and Lower Hutt, the results being given in Fig. 4. Two different degrees of catastrophe were considered, namely:

(i) Event No. 1:

Earthquakes causing $I_{\mathrm{mm}} \geqslant 9$ (Fig. 8 a)

(ii) Event No. 2:

Earthquakes causing $I_{\mathrm{mm}} \geqslant 10$ (Fig. $8 \mathrm{~b}$ )

As can be seen from Fig. 4 (a), the event most likely to cause intensity 9 in the target area is a Type B earthquake of nominal magnitude $M_{B}=7.8$ to 8.0 . Its annual probability of occurrence is $3.7 \times 10^{-4}$ i.e. an annual risk of one in 2700 .

As can be seen from Fig. 3, if the four largest earthquakes are lumped together their resultant annual probability of occurrence is one in 1000, i.e. an average return period of 1000 years. the $M_{B}=7.9$ events is both the most likely event and is also in the middle of the range of the four largest events, $M=7.9$ is taken as representing this 1800 year risk level.

Referring to Item (ii) above, Fig. 4 (b) shows the relative risks of different sizes to events causing intensity 10 in the target area. Using similar arguments to those above, the most likely event to cause $I \mathrm{~mm}=10$ was taken to be a Type $B$ earthquake of $M B=8.0$ with an effective average return period of 9000 years.

In summary the two catastrophe events determined were :

Event No. 1: $M_{B}=7.9, I_{m m} \geqslant 9$, Return period 1000 yrs

Event No. 2: $M_{B}=8.0, I_{m m} \geqslant 10$, Return period 9000 yrs

\subsection{Positioning the Catastrophe Events}

Finally the above two events had to be located in positions consistent with the assumptions used in their derivation.
Event No. I was located such that the intensity is about halfway between MM9 and MMlO in Wellington, its epicentre being located on the Awatere Fault about 110 kilometres southwest of Wellington.

Event No. 2 was located as shown in Fig. 5, such that the intensity is slightly greater than MMIO in Wellington, and its epicentre is on the inferred extension of the Wairau Fault under cook strait.

\subsection{DATA ON THE PROPERTIES}

The insurance company provided data on commercial and domestic properties in the study area on which they carried earthquake insurance for material damage. This data gave the age and structural type of each property which allowed them to be coarsely classified as to their earthquake resistance. A number of the most valuable properties were visited and assessed by visual examination by experienced engineers not only to make their estimated damage levels more reliable, but also to help confirm the validity of the desk methods for the remaining properties.

\subsection{DAMAGE COST V. INTENSITY}

An important part of this study was the establishment of a relationship for the damage cost for various types of construction as a function of earthquake intensity. To find such relationships appropriate to New Zealand, which could be used with confidence, proved to be an onerous task for the following reasons:

a. Few data exist on a world scale.

b. Even less data is available for New Zealand.

c. Most existing data is poorly documented and vaguely defined.

d. There is very wide scatter in the data.

e. Data does not exist for all New Zealand types of construction.

f. Data is virtually non existent for very high intensity shaking (because this occurs very rarely, especially in built-up areas).

\subsection{Damage Ratios for Buildings}

Some of the above difficulties are illustrated by Fig. 6 , which depicts damage cost data from three sources of high standing. It can be seen that there is a factor of 5 to 10 between the lowest and the highest values of $D$ at intensities up to about MMI0. The values for $D$ at higher intensities are based on very little data. (Note that $D$ is the ratio of damage cost to replacement value of the building). As well as the works of Whitman (1973), Wiggins (1978) and the very general statistics of Munich Reinsurance (1978), all referred to on Fig. 6, for the purposes of this study reference was also made to other works, notably those of Elms and Silvester (1978), Cooney and Fowkes (1981), and Sauter (1979) together with the source work for the latter by Sauter and Shah (1978). 

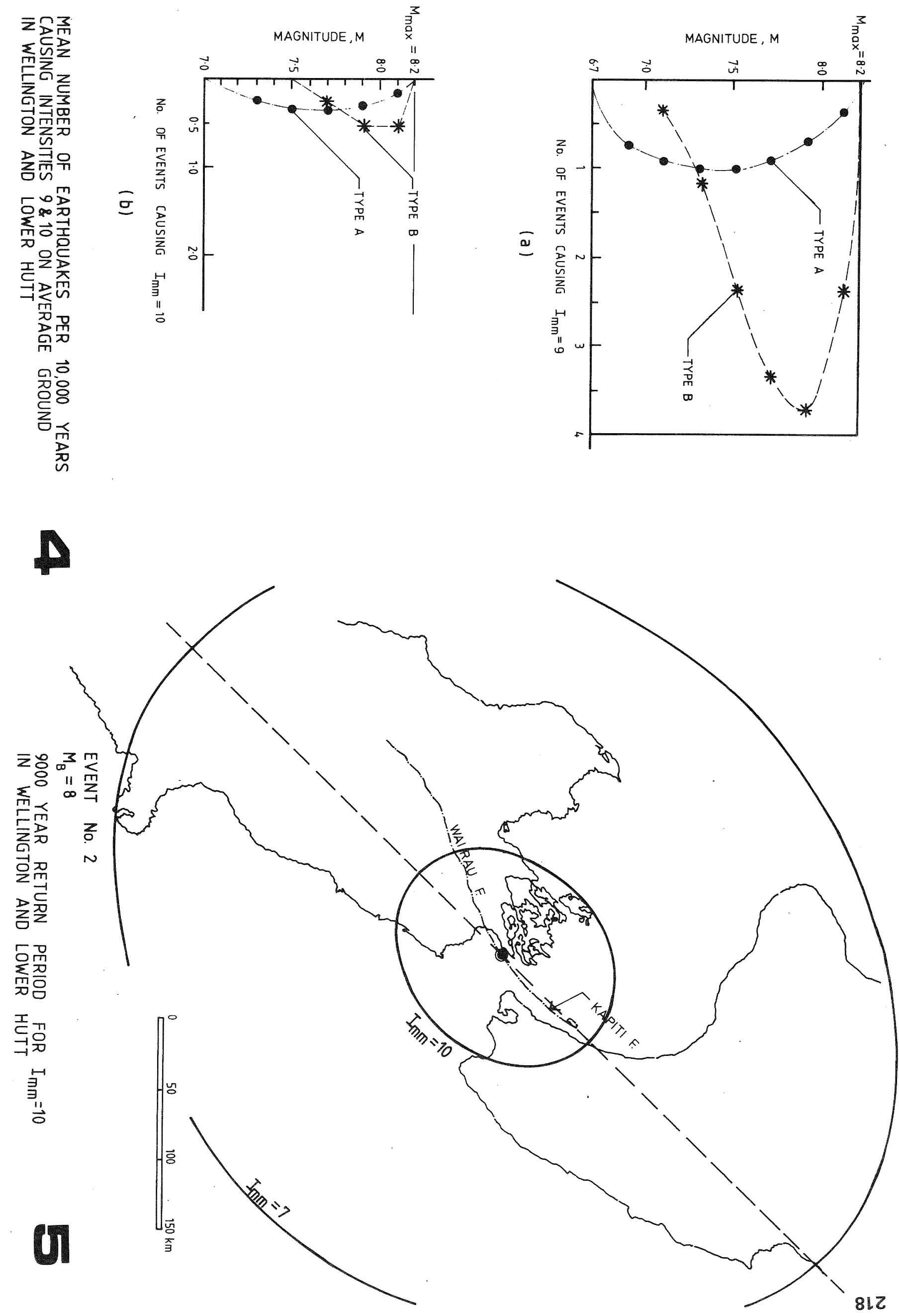
The latter work by Sauter and Shah was perhaps the most wide ranging of the above studies, but unfortunately is not only specific to Costa Rican buildings, but is not sufficiently descriptive of the exact types of buildings referred to for re-interpretation into New Zealand conditions. Furthermore the shape of their curves at higher intensities is illogical.

The damage ratio curves for commercial buildings finally developed for use in this study, were based on careful comparisons of all the data available, with allowance being made for differences in the construction standards of the buildings studied in each data set. An example for a specific age group is given in Fig. 7. This means that the curves in Fig. 7 are the subjective interpretations of data of poor quality, but no more valid approach seems to be available at the present time. As theoretical damage predictions are still very unreliable, only with the gathering of actual damage costs in comparable buildings in future high intensity earthquakes, will it be possible to produce damage curves which may be used with more confidence.

\subsection{Damage Ratios for Mechanical and Electrical Equipment}

The damage cost to equipment as a function of intensity was determined according to rules developed for this study, which were essentially an extension of the Modified Mercalli scale. As for buildings (as discussed above) the data for damage costs to equipment is sparse and the subjective judgement element in the figures used is again necessarily high.

\subsection{SUMMARY OF LIABILITIES}

The expected loss calculations were carried out on a parametric basis because of the uncertainties in much of the data. The set of results which was considered to give the most reliable total liability included an allowance for an exceptional rise in building costs, over-and-above inflation rate, which seems likely to occur after catastrophes of the magnitudes considered. For this purpose the book replacement values were enhanced by 20 percent.

After making allowances for the liabilities of the Earthquake and war Damage Commission the total liability for Event No. 1 (1000 year return period) was found to be approximately 25 percent of the enhanced total earthquake exposure of the insurance company in the area risk, or 39 percent of the apparent earthquake exposure. The total liability for Event No. 2 (9000 year return period) was approximately 38 percent of the corresponding enhanced total earthquake exposure or 58 percent of the apparent earthquake exposure.

It should be noted that most of the properties were insured for replacement in the event of total damage.

\subsection{Sensitivities}

The sensitivity of the estimated
Iosses to the uncertainties in the data and assumptions made was examined for:

(i) Variations in inflation during replacement period;

(ii) Variations in MM intensity;

(iii) Variations in the method sharing the liability between the insurance company and the Earthquake and War Damage Commission.

While each of these three uncertainties could have a large effect on the results, it is considered that a balance has been achieved which is likely to be slightly pessimistic overall.

\subsection{Fire Losses}

While some attempt was made to assess the losses due to earthquake-induced-fire, very little information was obtained despite efforts made through the good offices of the New Zealand Insurance Council. However, it was concluded that the losses due to fire might be perhaps 5-10 percent of the total and might well be implied in the damage ratios used.

\subsection{CONCLUSIONS}

(1) While smaller earthquakes are more common than larger ones in a given region, for any given point the risk of earthquake shaking increases with increasing magnitude (until close to $M \max$ ), because of the increasing area affected.

(2) For Wellington an intensity of MM9 is most likely to be caused by M7.9 earthquake and MMIO is most likely to be caused by an M8.0 earthquake.

(3) A large earthquake with a return period of 1000-10,000 years is likely to cause material damage liabilities of 40-60 percent of replacement value of properties in an area stretching approximately from Napier to Christchurch.

(4) Uncertainties in the earthquake constructional and insurance data could cause significant deviations from the above figures, but a greatly increased effort in this study would not have proportionally increased the reliability of the estimates.

(5) Significant reduction in the uncertainties involved in the above damage calculations are not likely to be achieved prior to the occurrence of a number of appropriately studied strong earthquakes centred on large numbers of buildings built similarly to those typical of New Zealand.

(6) The factor having the greatest uncertainty is actual damage costs for different classes of structure at high intensity levels.

\section{ACKNOWLEDGEMENT}

The courteous permission of New Zealand South British Insurance Group Ltd to publish this paper is gratefully acknowledged. 


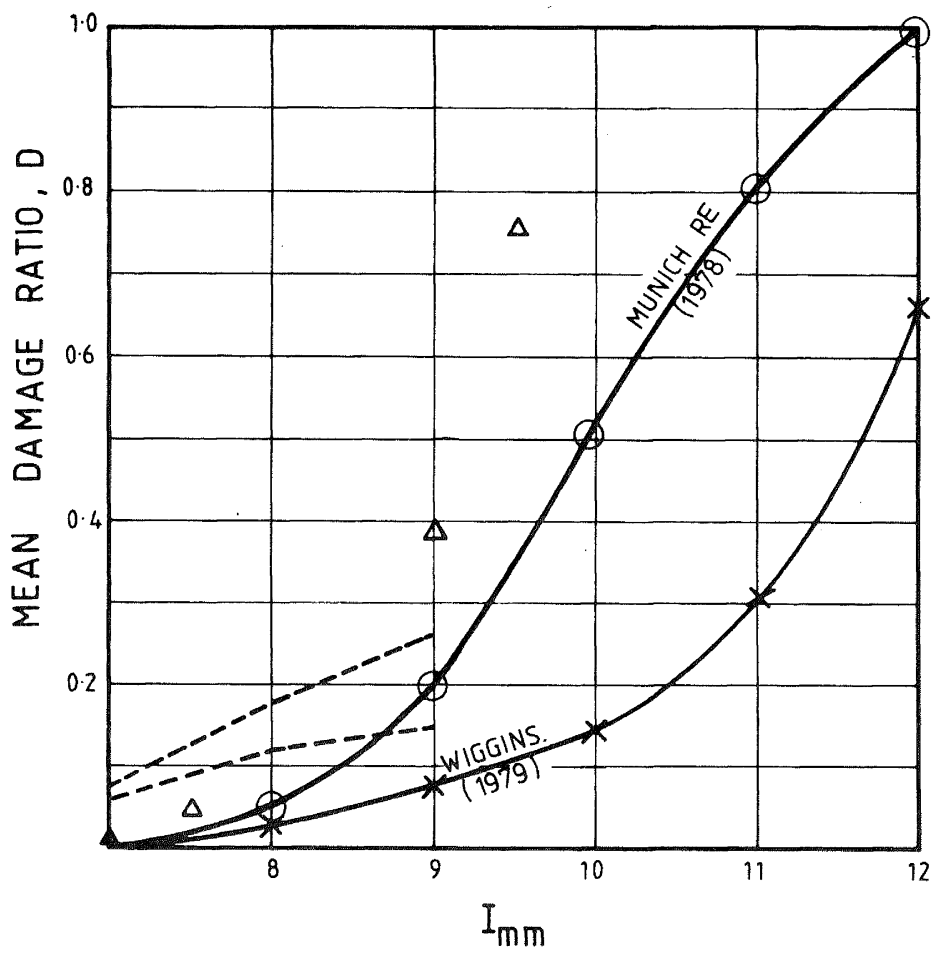

$\left.\begin{array}{cc}-- & \text { M.IT. CALCULATED VALUES } \\ \Delta & \text { SAN FERNANDO EARTHQUAKE }\end{array}\right\}$ (WHITMAN, 1973)
(7) REINFORCED MASONRY
( Office-House Style.)

(8) REINFORCED MASONRY (Factory Style.)

(9) REINFORCED CONCRETE.

(10) STEEL.

(11) TIMBER (Office-House Style.)

(12) TIMBER (Factory Style.)

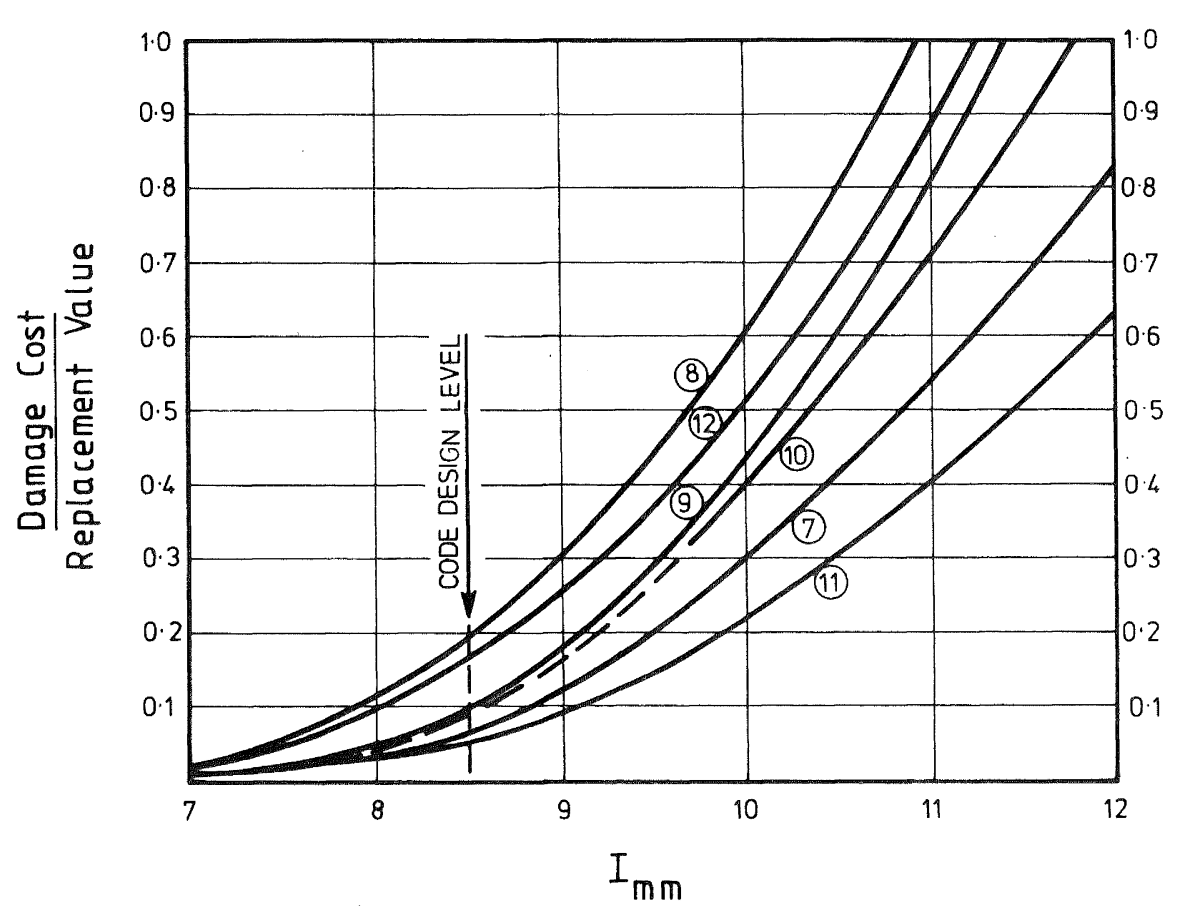

COMMERCIAL BUILDINGS

1966 - 1976

(WITHOUT FIRE LOSSES.) 


\section{REFERENCES}

1. Cooney, R.C. and Fowkes, A.H.R.

(1981) "New Zealand houses in earthquakes - what will happen?" in

"Large earthquakes in New Zealand", Royal Society of New Zealand.

2. Elms, D.G. and Silvester, D. (1978)

"Cost effectiveness of code base shear requirements for reinforced concrete frame structures", Bulln. NZ Nat. Soc. for Earthq. Eng. 11, 2, pp 85-93.

3. Evison, F.F. (1981) Institute of Geophysics, Victoria University of Wellington - Personal Communication.

4. Lensen, G.J. (1981) NZ Geological Survey - Personal Communication.

5. Munich Re (1978) Handbook to "World map of natural hazards", Munich Reinsurance Company.

6. Sauter, F. (1979) "Damage prediction for earthquake insurance", Proc, 2nd US Nat. Conf. on Earthq. Eng., Stanford, California.

7. Sauter, F. and Shah, H.C. (1978) "Estudio de seguro contra terremoto", Instituto Nacional de Seguros, San Jose, Costa Rica.

8. Smith, W.D. (1978 a) "Spatial distribution of felt intensities in New Zealand earthquakes", NZ Jnl Geol. and Geoph., 2l 3, pp 293-31l.

9. Smith, W.D. (1978 b) "Earthquake risk in New Zealand: statistical estimates", NZ Jnl Geol. and Geoph. , 21, 3, pp 313-217.

10. Smith, W.D. (1981 a) Seismological Observatory, Wellington - Personal Communication.

11. Smith, W.D., (1981 b) "The vast event How vast and how often? A statistical perspective of earthquake occurrence", in "Large earthquakes in New Zealand", Royal society of New Zealand.

12. Stevens, A.G. (1980) "New Zealand adrift", Reed, Wellington.

13. Whitman R.V. (1973) "Damage probability matrices for prototype buildings" Massachussets Institute of Technology, Dept. of Civil Engineering, Report 73-57.

14. Wiggins, J.H. (1979) "Estimated building losses from US earthquakes", Proc. 2nd US Nat. Conf. on Earthq. Eng., Stanford, California. 